\title{
Aproximación a una conceptualización de los derechos fundamentales
}

Approach to a conceptualization of fundamental rights

Abordagem a um conceituação de direitos fundamentais

\section{Beatriz Delgado Motoa ${ }^{1}$}

Recibido: 25 de enero de 2019

Aprobado: 18 de marzo de 2019

Publicado: 30 de junio de 2019

Cómo citar este artículo:

Beatriz Delgado Motoa. Aproximación a una conceptualización de los derechos

fundamentales. DIXI 29, Enero 2019, 1-13.

DOI: https://doi.org/10.16925/2357-5891.2019.01.03

Artículo de investigación. https://doi.org/10.16925/2357-5891.2019.01.03

1 Magíster en Derecho de la Universidad Sergio Arboleda, Bogotá, Colombia. Universidad Cooperativa de Colombia

Correo electrónico: bedelgadom@hotmail.com 


\section{Resumen}

Objetivo: el trabajo se orienta a establecer de forma clara el concepto de los derechos fundamentales, para lo cual toma como base las diferentes corrientes filosóficas que orientan el tema, además de lograr determinarlo en los países que conforman Unasur.

Metodología: estudia cuáles son las diferentes nociones existentes sobre estos derechos y cuáles se consideran fundamentales.

Hallazgos: el mundo, y en especial esta región, ha avanzado de forma considerable en la protección de los derechos fundamentales.

Conclusiones: se presenta la aproximación de un concepto común a todos estos países, a fin de lograr su protección de forma uniforme.

Palabras clave: derechos fundamentales, garantías constitucionales, Unasur.

\section{Abstract}

Objective: the essay is aimed at clearly establishing the concept of fundamental rights, based on the different philosophical currents that guide the subject, as well as being able to determine it in the countries that make up Unasur.

Methodology: the article study what are the different existing notions about these, which are considered as fundamental.

Results: the world, and especially this region, has made great progress in the protection of fundamental rights. Conclusions: the approximation of a common concept to all these countries is presented, in order to achieve its protection in a uniform way.

Keywords: fundamental rights, constitutional guarantees, Unasur.

\section{Resumo}

Objetivo: o trabalho visa estabelecer claramente o conceito de direitos fundamentais, por que se baseia nas diferentes correntes filosóficas que norteiam o assunto, além de determinar nos países que compõem a Unasur.

Metodologia: estudar quais são as diferentes noções existentes sobre esses direitos e quais são consideradas fundamental.

Constatações: o mundo, e especialmente esta região, fez progressos consideráveis na proteção direitos fundamentais.

Conclusões: é apresentada a abordagem de um conceito comum a todos esses países, a fim de alcançar seus objetivos. proteção uniformemente.

Palavras-chave: direitos fundamentais, garantias constitucionais, Unasur. 


\section{INTRODUCCIÓN}

Los derechos fundamentales, considerados como aquellos inherentes al ser humano en razón a su dignidad -y considerado también su concepto como el más importante de las constituciones contemporáneas- se adoptan en Colombia en la Constitución de 1991, de manera que la honorable Corte Constitucional fija unos criterios que permiten identificar su naturaleza. Es por esto que algunos derechos han sido denominados "de segunda generación", por haberse reconocido como derechos fundamentales derechos sociales que son necesarios para que la persona humana cuente con una vida digna.

El título II, capítulo I, de la Carta Política colombiana se ocupa - según se indica- de forma expresa de los "derechos fundamentales". Sin embargo, la Corte Constitucional de este país ha sostenido que la constituyente no determinó de manera taxativa cuáles eran los derechos constitucionales fundamentales, sino que fue su voluntad conferir simplemente un efecto indicativo a la ubicación y la titulación de las normas constitucionales. Por consiguiente, los derechos fundamentales no solo son los que aparecen en el título y los capítulos referidos, sino que, en vista de ello, la Corte Constitucional colombiana utiliza otros criterios para reconocer los derechos fundamentales.

Existen criterios principales y subsidiarios de interpretación, y se acogen como los principales aquellos que traten de un derecho esencial de la persona y el reconocimiento expreso de la constituyente. Además, acoge como criterios auxiliares los que no bastan por sí solos, como, por ejemplo, la inclusión del derecho en tratados internacionales; es decir, que se trate de un derecho de aplicación inmediata, que posea un "plus" para su modificación (se refiere a los que requieren de referendo para ser reformados), y, por último, la ubicación y denominación. Asimismo, para que un determinado derecho se tenga como fundamental, la honorable corporación constitucional colombiana considera que debe reunir tres requisitos: conexión directa con los principios constitucionales, eficacia directa y contenido esencial (núcleo básico del derecho) $)^{2}$.

1 Cf. Lizandro Cabrera-Suárez. La paz: mucho más que el final de la guerra. DIXI 18(23). 2016. Págs. 27-44.

2 Cf. Corte Constitucional de Colombia. SENTENCIA T- 406/92. (M.P.: Ciro Angarita Barón; junio 5 de 1992). 


\section{EVOLUCIÓN HISTÓRICA}

Al tomar como antecedente el origen del Estado y la sociedad que Aristóteles mencionó en La Política ${ }^{3}$, en el cual se indica que es una asociación, y como tal no se forma sino en vista de algún bien, pues todas las asociaciones tienden al bien de cierta especie, y el más importante de todos los bienes debe ser el objeto de la más importante de las asociaciones, de aquella que encierra todas la demás y a la cual el griego denomina "Estado" y" asociación política". Para el filósofo, en La Política, la constitución no es otra cosa que la repartición regular del poder a los asociados, bien sea en razón de su importancia particular, o bien en virtud de cierto principio de igualdad común; es decir, se puede dar una parte a los ricos y otra parte a los pobres, o dar a todos derechos comunes, de manera que las constituciones serán, necesariamente, tan numerosas como son las combinaciones posibles entre las partes del Estado, en razón a su superioridad respectiva y a sus diferencias ${ }^{4}$. De esto deviene una pluralidad de derechos y garantías en cabeza del Estado, sin imaginarse tan solo la globalización de los derechos fundamentales que se vive en la actualidad.

Esta organización política exige mecanismos de protección que otorguen garantías, a fin de pasar de un estado de naturaleza a un Estado organizado, en el que los derechos de los asociados tengan como límite el respeto de los derechos de las demás personas que conforman la asociación, tal como lo plateó en antaño Jean Jacques Rousseau en su contrato social, por el cual se sede en el goce de los derechos en pro de la protección colectiva de estos, y tiene como base fundamental de la sociedad a la familia 5 .

Desde no hace muchos años se han globalizado en el mundo moderno los denominados "derechos fundamentales", en torno a los cuales se han planteado diversas teorías filosóficas que los fundamentan. Cabe precisar que el presente tema se aborda como teoría jurídica de los derechos fundamentales, con base en la denominada "ley fundamental", entendida como la teoría del derecho positivo de los diferentes órdenes jurídicos a tratar, es decir, una teoría dogmática practicada como ciencia del derecho en sentido estricto. Esta teoría se concibe desde una dimensión inminentemente normativa, en cuanto disciplina práctica y como principio unificante, integrativa de los sistemas normativos de los Estados que han decidido confederarse en La Unión de Naciones Suramericanas, en la que, en un proyecto de cooperación de múltiples ejes que integra a los doce países independientes de sudamérica

3 Cf. Aristóteles. LA POLÍTICA. Editorial Cometa, Capítulo I, Libro Primero.

4 Id. Pág. 131.

5 Cf. Jean-Jacques Rousseau. El contrato social. Proyectos Ánfora. (2001). 
(República Argentina, República de Bolivia, República Federativa del Brasil, República de Colombia, República de Chile, República del Ecuador, República del Paraguay, República del Perú, República Oriental del Uruguay y República Bolivariana de Venezuela) con el objetivo de construir, de manera participativa y consensuada, un espacio de integración y unión en lo cultural, lo social, lo económico y lo político entre sus integrantes. En este propósito utiliza el diálogo político, las políticas sociales, la educación, la energía, la infraestructura, la financiación y el medio ambiente, entre otros factores, a fin de eliminar la desigualdad socioeconómica, lograr la inclusión social, la participación ciudadana y fortalecer la democracia6.

Robert Alexy ${ }^{\top}$ establece una teoría general de los derechos fundamentales, la cual apunta a una teoría integrativa que abarque, de la manera más amplia que sea posible, los enunciados generales verdaderos y correctos que puedan formularse, y la que, a su entender, podría denominarse "teoría ideal de los derechos fundamentales".

Según Alexy, la idea de esta teoría integrativa se puede enfrentar a dos malentendidos. Primero, creer que el postulado de la vinculación conduciría a una amplia y confusa mezcla de todos, en contravía de lo realmente perseguido, pues a todas luces de lo que se trataría es de implementar un sistema ordenado, claro, de enunciados universales, verdaderos y correctos sobre los derechos fundamentales. El segundo consiste en que el programa integrativo exige la teorización sobre los derechos y presenta a toda teoría existente sobre tales como insuficiente o carente de valor, a pesar de que sea verdadera o correcta, todo bajo el señalamiento de que no es amplia.

Aunado a lo anterior, Alexy abordó el tema de los principios. A fin de explicarlo introduce los principios como mandatos de optimización, e indica: "El punto decisivo para la distinción entre reglas y principios es que los principios son normas que ordenan que algo sea realizado en la mayor medida posible, dentro de las posibilidades jurídicas y reales existentes ${ }^{8}$. Por tanto, los principios, en cuanto mandatos de optimización, están caracterizados por el hecho de que pueden cumplirse en diferente medida, y que la mesura debida a su cumplimiento no solo depende de las posibilidades reales, sino también de las jurídicas.

6 Cf. Comunidad Andina. RUTA ANDINA. CONSTRUYENDo LA INTEgRACIÓN. (2010). Disponible en http://www.comunidadandina.org/sudamerica.htm

7 Cf. Robert Alexy. TEORía de los derechos fundamentales. Centro de Estudios Constitucionales. (1997).

8 Robert Alexy, en TEORÍA DE LOS DERECHOS FUNDAMENTALES, supra, nota 7, cita su obra "Zum Begriff des Rechtsprinzips", conferencia pronunciada en el 11 Congreso Mundial de la Asociación Internacional de Filosofía del Derecho y Filosofía Social, realizado en Helsinki en 1983. 
Visto esto, es evidente el papel preponderante desempeñado por los derechos fundamentales, entendidos como aquellos inherentes a la persona ${ }^{9}$, que le son propios por el solo hecho de existir, o como los que "constituyen la expresión más noble y cimera de la excelencia del hombre; cada uno de ellos aparece como un imperativo de justicia emanado de la primacía ontológica y moral del ser humano"10; asimismo, la obligación de los Estados de respetarlos y garantizar su protección.

Al ser clara la importancia del concepto de derechos fundamentales, estamos de acuerdo con lo expresado por el Dr. Lizandro Cabrera, quien expone:

[...] en la sentencia T-008 de 1992 de la Corte Constitucional, permite dilucidar que el uso de la expresión "derecho fundamental", obedece a cuestiones de carácter más técnico que filosófico, en tanto que el constituyente en aras de crear una jerarquización y una prevalencia normativa, para evitar confusiones interpretativas, catalogó una serie de derechos de esta manera, no queriendo decir que estos, fueran los únicos considerados fundamentales, sino simplemente marcando una pauta para identificarlos.

El término derechos fundamentales hace hincapié, pues, en el carácter primigenio de estos derechos, dado que resultan ser básicos y esenciales para el hombre y su realización plena. Bajo este entendido, los derechos fundamentales tienen un carácter historicista, de tal manera que pueden mutar, disminuir o aumentar de acuerdo con el desarrollo y las necesidades humanas. Así, lo que hoy no se considera derecho fundamental, mañana quizás sí lo sea, y viceversa. Por tal razón, en palabras de la Corte, "es conveniente adoptar una posición flexible y abierta" frente a esta denominación, pues de lo contrario se podrían dejar por fuera derechos que, en determinadas condiciones, tendrían esta naturaleza, dado el carácter evolutivo de la hermenéutica jurídica. Además, es necesario tener en cuenta que los derechos constitucionales fundamentales son, como los denomina la doctrina, un "concepto jurídico indeterminado"11; por tanto, "un derecho puede ser o no ser al mismo tiempo fundamental o tener, de forma simultánea, dicha naturaleza u otra, pero siempre su sentido se define bajo las circunstancias de tiempo, modo y lugar". Es importante resaltar que

9 Véase Lizandro Cabrera-Suárez. El desplazamiento en Colombia y sus diversas miradas. DIXI 25. 2017. Pág. 2.

10 Véase Mario Madrid-Malo. Derechos fundamentales. $1^{\text {a }}$ edición. Centro de Publicaciones de la ESAP. (1992).

11 Véase Corte Constitucional de Colombia. SENTENCIA T-002/92. (M. P.: Alejandro Martínez Caballero; mayo 8 de 1992). 
los derechos fundamentales se conciben, históricamente, como reivindicaciones que posibilitan la protección de las personas frente al poder del Estado, como una barrera contra la arbitrariedad y contra su conducta extralimitada, lo cual hace que el "concepto indeterminado" al que se hace referencia, se determine según su circunstancia de aplicabilidad.

Ahora bien, al ser claro que el concepto de derecho fundamental es abierto, por cuanto encierra diferentes concepciones y desarrollos, y no existe una forma exclusiva para su denominación, es importante el desarrollo que plantea el profesor Pablo L. Manili12, en el cual expresa:

Una de las definiciones que más nos satisface por su amplitud es la de Pérez Luño, que entiende a los derechos humanos como "... conjunto de facultades e instituciones que, en cada momento histórico, concretan las exigencias de la dignidad, la libertad y la igualdad humanas, las cuales deben ser reconocidas positivamente por los ordenamientos jurídicos a nivel nacional e internacional". El referido autor enriquece dicha definición aún más con la diferencia que traza entre los derechos humanos y los derechos fundamentales, a los que define como "aquellos derechos humanos garantizados por el ordenamiento jurídico positivo, en la mayor parte de los casos en su normativa constitucional... Se trata siempre, por tanto, de derechos delimitados espacial y temporalmente, cuya denominación responde a su carácter básico o fundamentador del sistema jurídico político del Estado de Derecho". [Cursivas añadidas]

Otra concepción de estos derechos los entiende como los garantizados en los diferentes ordenamientos jurídicos, específicamente en la norma constitucional, delimitados espacial y temporalmente y pertenecientes a cada uno de los individuos, y que deben gozar de especial protección por parte de los diferentes ordenamientos jurídicos.

Dada la amplitud del tema, el presente se aborda al observar la protección de los derechos fundamentales en los países que conforman la Unión de Naciones Suramericanas (Unasur), y es, por tanto, importante establecer en los diferentes países que lo atienden que los derechos fundamentales son, como se anotó, derechos humanos positivizados en un ordenamiento jurídico concreto. Es decir, son los derechos humanos concretados espacial y temporalmente en un Estado en particular. La

12 Profesor de Historia de Las Instituciones Políticas (UCES), de Derechos Humanos y de Garantías y de Derecho Constitucional (UBA). 
terminología de los derechos humanos se utiliza en el ámbito internacional porque lo que expresan es la voluntad planetaria de las declaraciones internacionales, la declaración universal de los derechos humanos frente al derecho fundamental.

\section{LA DIGNIDAD HUMANA Y LOS DERECHOS FUNDAMENTALES}

Finalmente, es importante resaltar que el reconocimiento de la dignidad humana, sin discriminación por razones de sexo, raza, origen, religión, opinión política o filosófica, debe ser el fin esencial de los Estados, de modo que deben establecer las condiciones necesarias e indispensables para el pleno desarrollo de los seres humanos que forman la sociedad. Es por esto que, si el objetivo de la civilización es lograr el completo desarrollo de la personalidad, con respeto por la dignidad humana, se inmiscuyen en compromisos tales como la necesidad de respetar los derechos fundamentales, tanto por parte del individuo como por parte de la comunidad, y la necesidad de respetar los contenidos de los actos políticos fundamentales que dan base jurídica al reconocimiento y la eficacia de los derechos fundamentales. Asimismo, si la soberanía reside exclusivamente en el pueblo ${ }^{13}$, los atentados de ese poder contra los derechos establecidos por el pueblo en su carta política constituirían violación de la soberanía interna, lo cual acarrearía el ejercicio de acciones para reprimir la violación, acciones que devienen de la soberanía popular.

\section{LA PROTECCIÓN DE LOS DERECHOS FUNDAMENTALES DESDE EL DERECHO COMPARADO}

La protección de derechos fundamentales en países como, por ejemplo, La República Argentina, la República de Bolivia, la República Federativa del Brasil, la República de Colombia, la República de Chile, la República del Ecuador, la República del Paraguay, la República del Perú, la República Oriental del Uruguay y la República Bolivariana de Venezuela, los cuales hacen parte de Unasur, se ha implementado en una acción, en algunos Estado de carácter constitucional y en otros de índole legal, formulada como un mecanismo para la protección de los derechos fundamentales.

13 Cf. Constitución Política de Colombia [Const.]. Julio 4 de 1991. (Colombia). Art. 3. 
En la República Bolivariana de Venezuela, por ejemplo, el amparo se adoptó en la Constitución de 1961, y se reglamentó a través de la Ley Orgánica de Amparo sobre derechos y garantías constitucionales. Además, se incluye un capítulo especial para el trámite del habeas corpus, y es la principal garantía constitucional protegida con la misma celeridad que el amparo ${ }^{14}$.

En Argentina se adoptó la acción de amparo como mecanismo de protección mediante la Ley 16.986 del 18 de octubre de 1966, aunque ya había sido asumido el amparo en varias provincias desde 1933. La Ley nacional de ese país consagró este mecanismo como acción de amparo con una restricción, pues su presentación es solo frente actuaciones de las autoridades públicas. No obstante, en algunas provincias se aplicaba a las actuaciones de los particulares; esta ley dispone:

La acción de amparo será admisible contra todo acto u omisión de la autoridad pública que, en forma actual o inminente, lesione, restrinja, altere o amenace, con arbitrariedad o ilegalidad manifiesta, los derechos o garantías explícita o implícitamente reconocidos por la Constitución Nacional, con excepción de la libertad individual tutelada por el habeas corpus ${ }^{15}$.

En Chile, el recurso de protección alude a lo que en derecho comparado se conoce como "recurso de amparo". Por otra parte, la principal norma en la legislación ecuatoriana que regula la acción de amparo se encuentra en la Constitución Política del Ecuador, en la que se lee:

Mediante esta acción, que se tramitará en forma preferente y sumaria, se requerirá la adopción de medidas urgentes destinadas a cesar, evitar la comisión o remediar inmediatamente las consecuencias de un acto u omisión ilegítimos de una autoridad pública, que viole o pueda violar cualquier derecho consagrado en la Constitución o en un tratado o convenio internacional vigente, y que, de modo inminente, amenace con causar un daño grave ${ }^{16}$.

14 Cf. Hernán Olano Correa y Alejandro Olano García. ACCIÓN DE TUTELA. Editorial Doctrina y Ley. (1995).

15 Véase Ley 16.986 de 1966 [República de Argentina]. Ley de acción de amparo. Octubre 18 de 1996. во del 20 de octubre de 1996.

16 Véase Constitución Política de la República del Ecuador. Septiembre 28 de 2008. (Ecuador.). Art. 95. 
De esta manera, da la posibilidad de proponer "acción" de amparo ante cualquier órgano de la función judicial y, tras un proceso, este pueda ser apelado ante el Tribunal Constitucional Ecuatoriano, entendiendo el legislador que se trata de un proceso diferente.

En Perú, la Constitución Política de 1993 ha mantenido el proceso constitucional de amparo introducido desde la Constitución de 1979. En este país la acción de amparo procede contra el hecho o la omisión por parte de cualquier autoridad, funcionario o persona que vulnera o amenaza los derechos fundamentales, distintos a los que protegen el habeas corpus y el habeas data, sin que proceda contra normas legales, ni contra resoluciones judiciales emanadas de un procedimiento regular.

En la República del Paraguay y la República Oriental del Uruguay su consagración es netamente legal, y se encuentra desarrollada en las leyes 1337 de 1988 y 16011 del mismo año, respectivamente. De igual forma, se tiene que en la República Federativa del Brasil la consagración es constitucional17. En Bolivia la acción de amparo es de manera neta de consagración constitucional18.

Por último, en Colombia la consagración del amparo a los derechos fundamentales es constitucional y legal ${ }^{19}$. Pues bien, cualquiera sea la connotación que exista de estos derechos en los diferentes países, la acción ha sido llamada "de amparo", "de tutela" y "mandato de seguridad", entre otros, y se consagra en procura de la protección de los llamados "derechos fundamentales".

Por su parte, el derecho internacional también ha consagrado elementos jurídicos de amparo como mecanismos de protección de los derechos fundamentales, como lo es el caso de la Declaración Universal de los Derechos Humanos ${ }^{20}$, la cual indica: "Toda persona tiene derecho a un recurso efectivo, ante los tribunales nacionales competentes, que la ampare contra actos que violen sus derechos fundamentales reconocidos por la Constitución o por la ley"21.

Asimismo, la Convención Americana sobre Derechos Humanos, suscrita en San José de Costa Rica, aprobada en Colombia mediante la Ley 16 de 1972, cuyo instrumento de ratificación fue depositado el 31 de julio de 1973, y en vigor para Colombia desde el 18 de julio de 1978, estableció:

17 Cf. Constitución Política de la República Federativa del Brasil. 1988. (Brasil).Título II.

18 Ley del Tribunal Constitucional de 1998.

19 Cf. Constitución Política de Colombia, supra, nota 13, art. 86.

20 Proclamada por la Asamblea General de las Naciones Unidas el 10 de diciembre de 1948, la que por su naturaleza no requiere ratificación por parte de los Estado miembros.

21 Véase UN. Asamblea General. DECLARAción UNIVERSAL DE LOS DEREChos humANos. Res. $217^{\mathrm{a}}$ (III). (Diciembre 10 de 1948). Art. 8. 
Protección judicial. Toda persona tienen derecho a un recurso sencillo y rápido o a cualquier otro recurso efectivo ante los jueces o tribunales competentes, que la ampare contra actos que violen sus derechos fundamentales reconocidos por la Constitución, la ley o la presente convención, cuando tal violación sea cometida por personas que actúen en ejercicio de sus funciones oficiales.

Comprueba lo expuesto que, sin importar la denominación que se le dé a la acción que se procure, lo importante es lograr la defensa y protección de los derechos fundamentales.

De acuerdo con la Convención Americana sobre Derechos Humanos de San José, los Estados partes se comprometen a:

a) A garantizar que la autoridad competente prevista por el sistema legal del Estado decidirá sobre los derechos de toda persona que interponga tal recurso;

b) A desarrollar las posibilidades de recurso judicial, y

c) A garantizar el cumplimiento, por las autoridades competentes, de toda decisión en que se haya estimado procedente el recurso"22.

Así, entonces, esta norma es fuente formal de la inclusión de la acción de tutela en diferentes países como mecanismo de protección de derechos, pero con diferentes denominaciones, competencias y efectos. Además de lo anterior, cabe anotar que algunas normas tienen rango constitucional, y en algunos casos se presentan como consagración legal y en otros como interpretación judicial.

\section{CONCLUSIONES}

Los derechos fundamentales se consideran los cimientos de las democracias modernas, así como normas principialísticas obligatorias. Son reivindicaciones que hacen posible la protección de las personas frente a los posibles excesos del Estado, garantizados en los diferentes ordenamientos positivos, en su mayoría, por consagración constitucional.

Gozan de protección por acción constitucional o legal, y es diferente su denominación (Ilamada "acción de amparo", "de tutela", "mandato de seguridad") según

22 Cf. OEA. CONVENCIÓN AMERICANA SOBRE DERECHOS HUMANOS DE SAN JOSÉ DE COSTA RICA. Noviembre 7 al 22. 1969. Art. 25. 
el país de aplicación (República de la Argentina, República de Bolivia, República Federativa del Brasil, República de Colombia, República de Chile, República del Ecuador, República del Paraguay, República del Perú, República Oriental del Uruguay y República Bolivariana de Venezuela, los cuales hacen parte de Unasur), pero con un mismo fin: la garantía y la protección de los derechos fundamentales de las personas.

En fin, los derechos fundamentales se pueden considerar abiertamente sin tener en cuenta las concepciones y los desarrollos exclusivos de cada país, por cuanto deben considerarse como derechos humanos concretados espacial y temporalmente en un Estado concreto.

\section{RECOMENDACIONES}

La lucha del hombre se ha cristalizado en la reivindicación de los derechos fundamentales. Por esta razón, en todos los escenarios posibles -la familia, la escuela, el trabajo, la academia - se debe trabajar en el desarrollo de ellos, en su difusión, en su aprendizaje. No son una moda, deben ser una realidad.

\section{REFERENCIAS}

un. Asamblea General. Declaración Universal de los Derechos Humanos. Res. $217^{\mathrm{a}}(\mathrm{III})$. (Diciembre 10 de 1948). Art. 8.

Aristóteles. LA PoLítICA. Editorial Cometa.

Comunidad Andina. Ruta Andina. Construyendo la integración. (2010). Disponible en http://www.comunidadandina.org/sudamerica.htm

Constitución Política de Colombia [Const.]. Julio 4 de 1991. (Colombia). Art. 3.

Constitución Política de la República del Ecuador. Septiembre 28 de 2008. (Ecuador.).

Constitución Política de la República Federativa del Brasil. 1988. (Brasil).

Corte Constitucional de Colombia. Sentencia T-002/92. (M. P.: Alejandro Martínez Caballero; mayo 8 de 1992).

Corte Constitucional de Colombia. SEnTEnCIA T-406/92. (M.P.: Ciro Angarita Barón; junio 5 de 1992). 
Hernán Olano Correa y Alejandro Olano García. Acción DE TUTELA. Editorial Doctrina y Ley. (1995).

Jean-Jacques Rousseau. El contrato social. Proyectos Ánfora. (2001).

Ley 16.986 de 1966 [República de Argentina]. Ley de acción de amparo. Octubre 18 de 1996. BO 20 de octubre de 1996.

Lizandro Cabrera-Suárez. La paz: mucho más que el final de la guerra. Dıxı 18(23). 2016. Págs. 27-44.

Lizandro Cabrera-Suárez. El desplazamiento en Colombia y sus diversas miradas. Dıxı 25. 2017. Pág. 2.

Mario Madrid-Malo. Derechos fundamentAles. $1^{\text {a }}$ ed. Centro de Publicaciones de la ESAP. (1992).

oea. Convención Americana sobre Derechos humanos de San José de Costa Rica. Noviembre 7 al 22. 1969. Art. 25.

Robert Alexy. Teoría de los derechos fundamentales. Centro de Estudios Constitucionales. (1997). 